\title{
PerCePÇÕES dOS ADOLESCENTES EM CONFLITO COM A LEI SOBRE SUAS VIVÊNCIAS NO CENTRO SOCIOEDUCATIVO DE CUIABÁ
}

\author{
Maria da Anunciação Pinheiro Barros Neta \\ Universidade Federal de Mato Grosso (UFMT), \\ Cuiabá, Mato Grosso, Brasil \\ Josiane TOMAZ da SILVA \\ Universidade Federal de Mato Grosso (UFMT), Cuiabá, \\ Mato Grosso, Brasil
}

\begin{abstract}
RESUMO: Este artigo descreve, compreende e interpreta as percepções dos adolescentes em conflito com a lei sobre suas vivências no Centro Socioeducativo de Cuiabá. A pesquisa é qualitativa de cunho dialético fenomenológico e se fundamenta principalmente no pensamento de Foucault, Paulo Freire, Graciani, e Volpi. As informações colhidas, mediante observação direta e entrevistas, mostram que a organização dessa instituição fomenta violência no seu interior e, ao invés de contribuir para ressocializar, potencializa o contínuo conflito com a lei. O desafio passa pelo Estado no sentido de realizar reformas sociais que propicie uma justa distribuição de renda e, nessa medida, possibilite ao adolescente superar a condição de vulnerabilidade, de exclusão social e educacional.
\end{abstract}

Palavras-chave: Percepções. Adolescentes em conflito com a lei. Vivências. Centro Socioeducativo. 
INTRODUÇÃO

A construção histórica da desigualdade social no mundo, no Brasil e em Mato Grosso, impede que as classes desfavorecidas, a partir de uma justa distribuição de renda, usufruam de condições mínimas de dignidade humana. Apesar de alguns avanços sociais e educacionais ainda há um longo caminho a percorrer para se chegar a um indicador satisfatório.

Em Cuiabá, a violência é o fator que tem afetado a sociedade de forma mais contundente. A prática de ato infracional por adolescentes tem assumido proporções preocupantes requerendo competências e habilidades mais específicas no trato com a questão. Essa preocupação cresce na medida em que se observa a gravidade dos atos infracionais cometidos por essa população que, consequentemente, ingressa nas Unidades de Internação.

O capitalismo internacional impõe regras de competição desleais no sentido de criar leis e regras que favorecem o Primeiro Mundo em detrimento dos países do Terceiro Mundo. Desse desequilíbrio de poder surgem duas situações: as classes dominantes se beneficiam de condições materiais fundamentais, como alimentação, saúde, educação, bens simbólicos e, para as classes subalternas restam a vulnerabilidade, fome, desemprego, péssima qualidade da educação, enfim, exclusão social.

Decerto, presenciamos o acirramento das desigualdades sociais, o empobrecimento das populações e o enfraquecimento dos laços afetivos e sociais das pessoas que consequentemente perdem sua história e identidade, o que proporciona a alienação e também um processo irreversível de fragilização.

Nessa condição de vulnerabilidade e exclusão social, os adolescentes acabam vivendo na e da rua, se prostituindo, se drogando e se tornando mão de obra fácil para o crime organizado, pois em razão de não terem condições mínimas de sobrevivência, são impulsionados a fazer qualquer coisa tanto para ajudar a família quanto para terem a satisfação das necessidades básicas que a família não lhes pode proporcionar.

Segundo Graciani (1997, p. 25), os adolescentes marginalizados, moradores de rua ou mesmo abrigados, mas em péssimas condições de vida são resultado do modelo de desenvolvimento adotado no Brasil, onde há uma expansão do Produto Interno Bruto (PIB), mas ao mesmo tempo os indicadores sociais deixam a desejar. Tais adolescentes, mais cedo ou mais tarde são impelidos, pelas condições de exclusão a entrarem em conflito com a lei. 
A questão da juventude em conflito com a lei tem sido objeto de diversos estudos, mas ainda se faz necessário ampliar e aprofundar o debate sobre a questão. Ainda conforme Graciani (1997, p. 25) “Há uma ausência de reflexão e debate voltado para identificar e possibilitar respostas às demandas, necessidades, inquietações e sonhos dos adolescentes e, em especial, dos adolescentes em conflito com a lei.

Pretendendo compreender e aprofundar o debate sobre a questão, buscamos investigar qual a percepção dos adolescentes em conflito com a lei sobre suas vivências no Centro Socioeducativo de Cuiabá.

Antes, porém, de descrever a pesquisa propriamente dita, vamos resgatar sucintamente, o pensamento de Michel Foucault sobre as prisões e o poder disciplinar dos corpos para melhor compreender a estrutura organizacional e o funcionamento do Centro Socioeducativo.

\section{AS PRISÕES E O PODER DISCIPLINAR DOS CORPOS}

A prisão surgiu na Europa no fim do século XVIII e início do século XIX com a função de punir os membros da sociedade para torná-los dóceis e úteis, por meio de um trabalho preciso sobre seu corpo.

Segundo Foucault (1987, p. 208), apesar das contradições que a prisão traz consigo, ela se consolida como "a detestável solução de que não se pode abrir mão"e, decorridos quase dois séculos de seu surgimento, a prisão continua sendo proposta como seu próprio remédio. Essa "obviedade" da prisão se fundamenta, em primeiro lugar, na simples privação de liberdade, permitindo quantificar a pena segundo a variável do tempo. Em segundo lugar, se baseia em seu papel, suposto ou exigido, de aparelho para transformar os indivíduos. Esse duplo fundamento, jurídico-econômico por um lado e técnico-disciplinar por outro, fez a prisão aparecer como a forma mais imediata e mais civilizada de todas as penas.

Uma coisa, com efeito, é clara: a prisão não foi primeiro uma privação de liberdade a que se teria dado em seguida uma função técnica de correção; ela foi desde o início uma "detenção legal" encarregada de um suplemento corretivo, ou ainda uma empresa de modificação dos indivíduos que a privação de liberdade permite fazer funcionar no sistema legal. Em suma, o encarceramento penal, desde o início do século XIX, recobriu ao mesmo tempo a privação de liberdade e a transformação técnica dos indivíduos. (FOUCAULT, 1987, p. 208). 
Foucault (1987, p. 209) assinalou que, a partir da emergência do capitalismo industrial e da sociedade disciplinar, as elites passaram a preocupar-se, não somente com as infrações cometidas pelo sujeito, mas também com aquelas que poderiam vir a acontecer.

Com a prisão, o indivíduo deverá ser punido, não apenas por seus atos, mas por suas intenções. Desta forma, deverá ser avaliado, não somente pelo crime que ele possa ter cometido, mas por seu potencial de periculosidade para a sociedade. Assim, o sistema prisional justifica a privação da liberdade e a reformulação das atitudes comportamentais dos indivíduos.

Normalmente as regras vigentes não se sustentam na formalidade teórica, mas nas situações e inter-relações concretas no cotidiano institucional. Qualquer desvio a uma dessas regras é considerado desobediência, exigindo do adolescente o aceite dos códigos sem questionamento de sua origem ou de sua pertinência. Dessa maneira, o corpo não passa mais por suplício como nas velhas formas de punição. Agora, a prioridade é a transformação da alma e do comportamento, dando a ideia de reformatório.

E para essa operação o aparelho carcerário recorreu a três grandes esquemas: o esquema político-moral do isolamento individual e da hierarquia; o modelo econômico da força aplicada a um trabalho obrigatório; o modelo técnico-médico da cura e da normalização. A cela, a oficina, o hospital. A margem pela qual a prisão excede a detenção é preenchida de fato por técnicas de tipo disciplinar. E esse suplemento disciplinar em relação ao jurídico, é a isso, em suma, que se chama o"penitenciário". (FOUCAUU, 1987, p. 220-221).

Segundo Foucault (1987, p. 190), para ser possível a correção é preciso que seja criado um espaço de prisão em que um guarda tenha condições de observar os prisioneiros sem que eles tenham certeza se estão sendo vigiados. Esse espaço denominado panóptico foi desenhado pelo filósofo Jeremy Bentham em 1785.

O panóptico tem a possibilidade, ao mesmo tempo, de vigilância e observação, segurança e saber, individualização e totalização, isolamento e transparência. A prisão é seu local privilegiado de realização porque propicia a um vigilante controle de tudo o que se passa com os prisioneiros no Centro Penitenciário. Ele tem uma estrutura arquitetônica em forma de anel e, no meio dele há uma torre central com um vigilante. Esse anel divide-se em pequenas celas e permite que o olhar do vigilante as atravesse tanto para o interior quanto para o exterior. Essa forma arquitetônica das instituições vale para as escolas, hospitais, prisões, fábricas, hospícios. 
O panóptico é um exercício constante de afirmação de um poder ramificado que se multiplica, se fixa, distribui e organiza espaços, impõe comportamentos. "A escola tende a constituir minúsculos observatórios sociais para penetrar até nos adultos e exercer sobre eles um controle regular". (FOUCAULT, 1987, p. 186)

Atualmente, o princípio da transparência e da visibilidade está muito mais enraizado: os cartazes de que as pessoas estão sendo filmadas estão por todos os lados e, o mais curioso, é que as pessoas exigem cada vez mais câmeras. Outro resultado desse princípio são os programas de televisão que exploram com grande sucesso e audiência a exposição de pessoas sendo vigiadas permanentemente. Isso ocorre também nas escolas, pois se acredita que quanto maior for a vigilância, maior a segurança.

\section{DESVENDANDO AS EXPERIÊNCIAS VIVIDAS PELOS ADOLESCENTES NO CENTRO SOCIOEDUCATIVO}

Esta pesquisa pretende descrever, compreender e interpretar as percepções dos adolescentes em conflito com a lei sobre suas vivências no Centro Socioeducativo de Cuiabá.

A metodologia utilizada é qualitativa de cunho dialético fenomenológico, uma vez que a fenomenologia tem princípios e significados que os sujeitos atribuem a sua experiência vivida. Ela pode ser caracterizada como um estudo detalhado de um determinado fato, objeto ou grupo de pessoas visando buscar informações para compreender e interpretar o fenômeno. Para tanto, apoiar-nos-emos no pensamento de Foucault, Graciani, Volpi e Freire.

A pesquisa foi realizada no Centro Socioeducativo Educativo de Cuiabá que se encontra localizado no Complexo Pomeri, em dois ambientes: GAMA - Gerência de Atendimento em Meio Aberto e a Escola Estadual Meninos do Futuro. A GAMA foi criada em 2002 mediante uma Gerência com o objetivo de atender, de forma multidisciplinar os adolescentes Egressos da Internação de Cuiabá e a Escola Estadual Meninos do Futuro foi criada pela SEDUC - Secretaria Estadual de Educação em 1995 com a finalidade de oferecer o Ensino Fundamental, Ensino Médio Regular e a Educação de Jovens e Adultos (EJA) para adolescentes em situação de prisão. Atualmente atende 95 adolescentes do sexo masculino e 12 adolescentes do sexo feminino.

Para a realização das entrevistas fez-se necessário entrar com documentação formal junto ao diretor da Unidade de Internação que deu permissão com algumas recomendações, portanto, e ra expressamente proibido: 
utilizar gravador, celular, blusa preta, usar brincos ou acessórios (exceto óculos de grau) e calçados de salto alto. Além disso, devíamos ficar alertas para qualquer movimento diferente, pois poderia tratar-se de uma rebelião.

A prisão deve ser concebida de maneira a que ela mesma apague as consequências nefastas que atrai ao reunir num mesmo local condenados muito diversos: abafar os complôs e revoltas que se possam formar, impedir que se formem cumplicidades futuras ou nasçam possibilidades de chantagem (no dia em que os detentos se encontram livres). (FOUCAULT, 1987, p. 211)

Foram entrevistados 15 adolescentes internos julgados (com reclusão de, no máximo, três anos) escolhidos e revistados pelos agentes prisionais. Também foram entrevistados 15 adolescentes egressos da GAMA. Tais adolescentes não tinham dia e nem hora marcada para vir ao atendimento, mas eram obrigados a vir uma vez ao mês. Nesse sentido, o processo de entrevista com eles foi bem mais difícil e demorado. Foram necessárias três semanas de plantão (manhã e tarde) para entrevistar a quantidade planejada. As entrevistas eram realizadas no auditório do Centro Socioeducativo, na sala da gerente da GAMA e na cozinha, pois somente nesses locais era possível ficar a sós com os adolescentes.

Com base na observação direta e entrevistas buscamos compreender e interpretar os discursos dos adolescentes sobre as seguintes palavras geradoras: conflito com a lei; percepção de si mesmos; de como as pessoas os percebem; como percebem a educação; como percebem a evasão e repetência escolar; educação que gostariam de ter ou se não gostariam de ter educação; perspectivas de vida.

\section{Conflito com A LeI}

Quando questionados sobre se já haviam cumprido alguma medida socioeducativa, dos quinze internos, dez já tinham cumprido medida. Dos egressos, doze já tinham cumprido Medida Socioeducativa e apenas três não. O tempo médio de internação é de três a seis meses e o de cumprimento de medida dos egressos é de no mínimo seis meses. A seguir, apresentamos os relatos obtidos nas entrevistas sobre o que os levou a entrar em conflito com a lei.

Era muito criança, mente fraca, fui levado pela cabeça dos outros. Me senti forçado, porque a gurizada ficava falando que eu não era de nada, que eu ia ganhar dinheiro e se eu não fizesse, eu era um bobo (Egresso, 14 anos) 
Um minuto de bobeira, meu pai tinha confiança em mim. Peguei o carro dele pra carregar as coisas que um pessoal tinha roubado de uma casa. Não me senti forçado, mas também não tive prazer, falaram que ganharia uma grana boa (Interno, 16 anos)

Podemos perceber pelos relatos que a transgressão das normas ocorre em razão dos adolescentes estarem atravessando um período de transição no qual eles ainda não atingiram maturidade para exercer vontade própria. Nessa perspectiva, Volpi (2005, p. 14) afirma que: "A criança e o adolescente são concebidos como pessoas em desenvolvimento, sujeitos de direitos e destinatários de proteção integral". Portanto, como ser em desenvolvimento está sujeito a cometer falhas e delitos, a testar os limites e a quebrar regras. Esse período é transitório, pois um adolescente que transgride normas mostra-se em conflito com a lei e o delinquente já cometeu vários delitos.

Sei lá, de repente você já tá dentro, muitas coisas, desigualdade, você vai porque você quer as coisas, é duro você querer as coisas e nunca poder ter, não ter dinheiro, só a coroa trabalhando não dá. Não é forçado, é o dia-a-dia, se você não faz você morre" (Egresso, 16 anos)

Fiz um assalto. Em casa sem nada, minha mãe desempregada, só um irmão trabalhando, ganhando pouco. Dá uma revolta na gente. Os amigos ficavam chamando em casa e a vida não tava muito boa (Egresso, 17 anos)

Os adolescentes egressos mostram em suas narrativas que tomaram a decisão de cometer delitos pela necessidade de superar condições econômicas e sociais desfavoráveis, mas compreendemos que, para além das necessidades de sobrevivência, muitos adolescentes são também impulsionados pela cultura do ter, do imediatismo, do consumismo, onde uma pessoa vale pelo que possui. Em termos de homicídio, o relato desse adolescente é preocupante:

Me senti forçado pra defender a vida de um amigo. Me arrependi de ter matado ele (o rival do amigo), um ano a mais que eu puxar aqui no Centro Socioeducativo não vai trazer a vida do cara de volta, a mãe dele nunca vai ver ele. A vida do crime não compensa, eu tinha tudo, mas aqui você não tem nada, eu não tenho nem TV. Comecei a mexer com droga no início do ano passado. Tirava em uma semana de seis a oito mil, só tenho roupa cara em casa, cordão de ouro tenho três. Quando chegar em casa quero me desfazer de tudo. Por causa dessa vida dei 22 facadas em um cara. Dei 17, fumei um baseado e depois dei mais cinco (Interno, 16 anos) 
O adolescente justifica o crime sob pretexto de defesa de um amigo, mas chama à atenção a frieza com a qual cometeu o crime, como se experimentasse a delinquência com prazer. Ele se diz arrependido e acredita que terá uma vida diferente se desfazendo de tudo o que foi furtado durante o período em que esteve no mundo do crime. Foucault fala sobre a natureza do delinquente e não apenas o que o sistema cria.

O delinquente se distingue também do infrator pelo fato de não somente ser o autor de seu ato (autor responsável em função de certos critérios da vontade livre e consciente), mas por estar amarrado a seu delito por um feixe de fios complexos (instintos, pulsões, tendências, temperamento). A técnica penitenciária se exerce não sobre a relação de autoria, mas com a afinidade do criminoso com seu crime. (FOUCAULT, 1987, p. 224).

\section{PeRCEPÇÃO de SI MESMOS}

Entrevistados sobre como percebem a si mesmos, a palavra geradora mais relatada nos discursos dos adolescentes egressos atestam:

Sou uma pessoa como todo mundo, sou um cara de boa. Minha vida mudou muito. Antes de ser preso eu vendia droga, comecei com 14 anos e parei de estudar. Hoje tô indo à igreja. (Egresso, 17 anos).

Eu sou hoje um cara mais tranquilo. Antes era muito alterado. Depois que fui preso melhorei bastante. (Egresso, 15 anos).

Ótima pessoa, elegante, inteligente, trabalho também, trabalho com meu padrasto de servente de pedreiro de $2^{\mathrm{a}}$ a $6^{\mathrm{a}}$ e é uma vida boa. Todo final de semana tem dinheiro para gastar, não precisa pegar de ninguém. (Egresso, 16 anos).

A partir das narrativas dos adolescentes, compreendemos e interpretamos que a experiência da internação possibilitou uma transformação de comportamento, mostrando que a opressão no sistema prisional pode, contraditoriamente, desencadear um processo de reflexão.

A justa duração da pena deve, portanto variar não só com o ato e suas circunstâncias, mas com a própria pena tal como ela se desenrola concretamente. O que equivale dizer que, se a pena deve ser individualizada, não é a partir do indivíduo-infrator, sujeito jurídico de seu ato, autor responsável do delito, mas a partir do indivíduo punido, objeto de uma matéria controlada 
de transformação, o indivíduo em detenção inserido no aparelho carcerário, modificado por este, ou a ele reagindo. (FOUCAULT, 1987, p. 218).

Questionados sobre como percebem a si mesmos, a palavra geradora mais relatada pelos adolescentes internos apontam o seguinte:

Guri de boa, sossegado, não mexe com a vida de ninguém se ninguém mexer com a vida dele, é de família, tenta evitar briga, aguenta o máximo que pode, vê a vida destruída porque a mãe vem na visita e só fica chorando e isso dá muito desânimo. (Interno, 16 anos).

Sossegado, calmo, tranquilo, escolhi o caminho errado - porque não ouvi os conselhos da mãe. Agora não vou ouvir conselho de técnica judiciária. Aqui a gente fica só na sua, se não souber viver aqui dentro, fica só no seguro, isolado. (Interno, 17 anos).

Foucault (1987, p. 212) explicita que:

[...] A solidão realiza uma espécie de auto-regulação da pena, e permite uma como que individualização espontânea de castigo: quanto mais o condenado é capaz de refletir, mais ele foi culpado de cometer seu crime; mas mais também o remorso será vivo, e a solidão dolorosa; em compensação, quando estiver profundamente arrependido, e corrigido sem a menor dissimulação, a solidão não lhe será mais pesada.

Compreendemos que o Centro Socioeducativo segue os mecanismos apresentados por Foucault quando coloca que o isolamento do adolescente privado de liberdade é uma maneira de diminuir a rebeldia e a insolência para que "aprenda" o que pode ou não fazer. Vejamos esse relato:

Eu sou sistemático, brincalhão, mas às vezes chato, sei lá, carinhoso, mas depende da pessoa. Muito estressado, mas consigo me controlar, não gosto de ninguém que fale demais. Minha realidade é boa, tem uma mãe que gosta de mim, tenho amigos fiéis que não são falsos, tenho compreensão da família. Aqui: não vejo, não ouço, morro cadeado. (Interno, 15 anos).

Esse adolescente compreendeu claramente como funciona o sistema disciplinar, e quanto mais dócil, mais submisso, melhor pra ele; "é dócil um corpo que pode ser submetido, que pode ser utilizado, que pode ser transformado e aperfeiçoado" (FOUCAULT, 1987, p. 127). Aperfeiçoado ao ponto de falar que dentro do sistema de internação, nada se vê, nada se ouve, é preferível morrer em silêncio. Outro adolescente interno expressa: "Sou um menino bom, trabalhava, não mexia com roubo, droga, nunca precisei 
ficar no coloio da gurizada. Quero sair daqui e mudar de vida. Qualquer hora posso levar uma pregada. Eu to perto de sair, mas pode acontecer alguma coisa comigo". (Interno, 18 anos).

No Centro Socioeducativo já existe uma cultura de que o adolescente que não se adapta ao grupo, que é delator, ou mesmo não quer se envolver com o que ocorre lá, sofre com a famosa e temida "pregada" que são pedaços de ferro que eles tiram das paredes, das camas de concreto e utilizam como armas para furar os companheiros de cela ou de uma gangue rival. Por isso, eles são agrupados dispostos em alas e cada ala tem seus inspetores, seus professores, tudo para evitar que aconteçam as "pregadas". A palavra geradora desse adolescente revela a violência no seu mundo vida: "De boa: gosto de brincar, de soltar pipa, jogar bola, de vez em quando, fazer uma arte. Aqui é muito ruim, não vou voltar mais pra cá não, tenho que ficar de boa, meu bairro é cabuloso, se eu não sair dessa vida, ou me matam ou eu mato alguém". (Interno, 16 anos).

Com base nesse relato, interpretamos que ainda há nele uma infância latente que quer ser vivida, porém a realidade que o espera fora da internação parece não proporcionar esperança da vivência que ele gostaria de ter.

A falta de realização da pessoa humana em seus direitos fundamentais se inicia antes do crescimento do homem por incentivo de evitar a concepção ou interrompê-la através do aborto; prossegue com a desnutrição infantil, e abandono prematuro, a carência de assistência médica, educação e moradia, propiciando desordem constante donde não é de se estranhar a proliferação de criminalidade, de prostituição, do alcoolismo e da drogatização. (GRACIANI, 1997, p. 106).

O artigo 227 da Constituição Brasileira afirma promover proteção integral às crianças e adolescentes que vem para uma instituição socioeducativa, mas quando não se tem a estrutura necessária, há uma "dupla punição": a falta de condições para sair da criminalidade e a entrada em um sistema de internação. Um dos adolescentes internos descreve sua percepção de si mesmo e da realidade em que vive:

Cresci revoltado com a vida desde os 5 anos. Por causa do meu pai, porque quando eles se separaram meu pai ficava tentando matar minha mãe, aí fui revoltado querendo matar meu pai e fui entrando pro mundo do crime e quando fui ver já tava aqui dentro. Liberdade é tão bom e a gente não dá valor, ainda mais agora que tenho filho de três meses, fugi mais pra ver o nascimento dele (Cairo). A mãe do Cairo não vem aqui porque é menor. 
Aqui é muita humilhação pra fazer visita. Já pedi pra minha mãe não vir. (Interno 17 anos)

Compreendemos claramente uma repetição da situação vivida pelo adolescente de sua infância, onde ele não teve assistência paterna, viveu em um lar onde a violência era constante. Hoje ele está interno, distante do filho que está desassistido de pai e com uma história que poderá se repetir em maior ou menor proporção. Graciani $(1997$, p. 25) nos expõe motivos para essa repetição do modelo parental:

Encontramos elementos explicativos que ajudam a entender o fenômeno pobreza e as consequências advindas de uma política econômica concentradora de renda, que forma uma sociedade baseada na desigualdade, penalizando os desprivilegiados produzidos por essa mesma sociedade. Os efeitos da pobreza aparecem em forma de cascata ao se reproduzirem por gerações, numa perspectiva senão de perpetuação, mas de multiplicação, que se materializa nas formas e estilos de vida que assumem as sucessivas gerações de famílias pobres.

\section{COMO AS PESSOAS OS PERCEBEM}

Questionados sobre como as pessoas os percebem, grande parte dos adolescentes narra uma mudança na forma como eram percebidos no mundo vida.

Falaram que eu mudei, minha tia ficou orgulhosa quando me viu ir pra igreja e voltar a estudar, acho que eu tava perdido no mundo" (Egresso, 16 anos)

Tem um ditado que diz: me diz com quem anda que eu te direi quem é. Mudei de bairro, antes eu não era boa coisa não" (Egresso, 16 anos)

Segundo Foucault (1987, p. 209),"a ordem que deve reinar nas cadeias pode contribuir fortemente para regenerar condenados; [...] o contágio dos maus exemplos, a ociosidade... originam crimes".

O Estatuto da Criança e do Adolescente (ECA) foi criado justamente porque o adolescente está em desenvolvimento, por isso o comportamento disruptivo dele é passageiro e Volpi $(2005$, p. 07) também tem este entendimento "A prática do ato infracional não é incorporada como inerente à sua identidade, mas vista como uma circunstância de vida que pode ser modificada". Outros discursos de internos e egressos descrevem o preconceito, o estigma social com que as pessoas os tratam: 
Só fala mal, que é vagabundo, que não é pra ficar perto porque se não vou levar pro mal caminho, mas eu não ligo porque sei quem tem a vida mais torta do que eu. A sociedade aponta você com outro olho, esse não presta, é bandido (Interno 16 anos)

Muita gente vê e baixa o rosto, vira as costa, outros saem correndo, acho que tem preconceito (Egresso 18 anos)

Segundo Volpi (2005, p. 09), "[...] É difícil, para o senso comum, juntar a ideia de segurança e cidadania. Reconhecer no agressor um cidadão parece ser um exercício difícil e, para alguns, inapropriado". Foucault (1987, p. 224) também deixa claro que "o sistema prisional, carcerário, cria o delinquente e, consequentemente, se acha no direito de julgar não o que eles fizeram, mas quem eles são e serão [...] Começam a julgar coisa diferente além dos crimes: a "alma" dos criminosos. Compreendemos que o ato infracional cometido pelo adolescente o acompanha e não sem dificuldade conseguirá romper as barreiras colocadas pela sociedade.

\section{PercepÇÃo dA educaçÃo}

Questionados sobre como percebem a educação escolar, a palavra geradora mais narrada pelos adolescentes revela que o ensino escolar não faz sentido para a vida deles. Vejamos os relatos seguintes: "A escola é importante, mas não tem nada a ver com minha vida. Não vejo o estudo da escola com meu dia a dia. Vou lá, copio o que a professora manda e vou embora" (Egresso 14 anos).

Freire $(2005$, p. 82) inovou quando disse que a educação bancária é um ato de depositar o conhecimento [...] O educador vai "enchendo" os educandos de um saber em que os conteúdos são impostos" (FREIRE, 2005, p. 82) e Volpi $(2005$, p. 30) declara que "a finalidade maior do processo educacional, inclusive daqueles privados de liberdade, deve ser a formação para a cidadania", mas pelos relatos dos adolescentes isso não se está concretizando. "Não gosto de ir à escola não sabe, mas ficou determinado que se não voltasse a estudar ia voltar pra cá." (Egresso 17 anos).

Vemos aí claramente a sanção normalizadora trazida por Foucault e exposta anteriormente, na qual aquele que não tem um bom comportamento será punido e sabendo disso os adolescentes se mostram dóceis à obrigatoriedade de ir à escola. "O castigo disciplinar tem a função de reduzir os desvios. Deve, portanto, ser essencialmente corretivo." (FOUCAULT, 1987, p. 209). Desta forma, ir à escola é uma maneira de corrigir o comportamento 
rebelde, visto que o adolescente que tem bom comportamento e frequenta a escola regularmente pode diminuir seu tempo na internação.

Há outra palavra geradora, entretanto, que mostra a importância da escola para as suas vidas por motivos diversos, como ajudar os familiares, aprender a ler e escrever pra não ser enganado, prejudicado financeiramente. Um adolescente entrevistado diz gostar da matemática porque ela te dá saber para lidar com os negócios do tráfico.

A matemática tem a ver, porque no tráfico você precisa aprender a fazer conta pra ninguém te passar pra trás. (Interno, 17 anos).

Tem porque quero ver se ajudo minha família, esse mundo de crime até compensa, mas é muito curto, eu quero arrumar um serviço melhor, sair dessa vida de dinheiro fácil. (Interno, 15 anos).

\section{EVASÃO E REPETÊNCIA ESCOLAR}

A evasão e repetência escolar são palavras geradoras muito presentes nos discursos dos adolescentes. Do total de 30 adolescentes, apenas seis estão cursando o Ensino Médio e oito não reprovaram. Os motivos que os levaram a sair da escola são distintos: desinteresse, uso de drogas, más companhias, trabalho no tráfico, briga de gangues, expulsão. A narrativa desse adolescente mostra bem essa realidade:

Saí porque não gostava da aula e tinha muita briga de gangues - não queria ninguém pegando no pé e porque viajava muito a trabalho, mexia com o tráfico aí matava muita aula. (Interno, 17 anos).

Saí porque eu era bagunceiro, não respeitava professor.Fui expulso da escola e o Conselho me obrigou a voltar. (Interno, 16 anos).

Saí da escola porque tinha muita treta - briga de gangues. Só por eu ser de outro bairro já é motivo pra arrumar briga. (Egresso, 16 anos).

No entanto, conforme Graciani (1997, p. 139-140):

A escola também é considerada como fonte de violência, quando discrimina, exclui e maltrata [...] O maior abuso contra a criança e o adolescente ocorre quando sua personalidade é destroçada pelo reforço da escola excludente, com sua cidadania tolhida e seus direitos desrespeitados e até aviltados e violados. 
Esses depoimentos demonstram resistência às regras e normas das instituições sociais demonstrando maior probabilidade de entrar em conflito com a lei. Tais resistências e conflitos não se dão apenas contra as normas da escola, mas também nos relacionamentos interpessoais. "As amizades que eu tinha foram me levando para o mau caminho" (Egresso 15 anos).

Isso indica que esses adolescentes provavelmente não recebem acompanhamento de perto, ficam muito sozinhos ou na companhia de colegas. Além disso, mostram-se resistentes ao adestramento mostrado por Foucault. Um dos adolescentes, por exemplo, chegou a desligar, furtar e a vender as câmeras de segurança do sistema da vigilância.

Não existe uma ferramenta maior que a vigilância por meio de câmeras de segurança, e o fato do adolescente roubar e vendê-las é o extremo da resistência ao poder disciplinador e cerceador da liberdade.

Percebemos, a partir das informações coletadas nas entrevistas que o contexto e as experiências vividas pela maioria dos adolescentes influenciam diretamente no processo de evasão e repetência, onde os estímulos recebidos na escola não são suficientes frente aos obstáculos econômicos e sociais enfrentados, necessitando de uma educação que permita um processo de ressignificação e humanização de si e dos outros.

\section{EDUCAÇÃO QUE GOSTARIAM DE TER (OU SE NÃO GOSTARIAM DE TER EDUCAÇÃO)}

Quando perguntados sobre como seria a educação formal que gostariam de ter ou se não gostariam de ter educação formal, a palavra descrita mais significativa critica a memorização:"Por mim não existia escola, tinha que ser outro meio de praticar o aprendizado, não tenho ideia de como seria, mas não só copiar e ouvir o outro falar". (Egresso, 17 anos)

O discurso dos adolescentes expressa a crítica de Freire $(2005$, p. 66) à educação bancária "em lugar de comunicar-se, o educador faz"comunicados" e depósitos que os educandos, meras incidências, recebem pacientemente, memorizam e repetem" (2005, p. 66). Um adolescente atestou um posicionamento diferente: "Acho que tinha que ser como era antes, estudar o ano todo e se não passar reprova". (Egresso, 16 anos).

Vemos que esse adolescente já introjetou os recursos para o bom adestramento expressos por Foucault $(1997$, p. 166) que são a vigilância hierárquica, a sanção normalizadora e o exame, este em especial, que qualifica, mede, compensa e gratifica; pune e reprova. Outra palavra recorrente mostra 
a deterioração da infraestrutura de muitas escolas:"A escola tem que melhorar mais alguma coisa, ter uma área de lazer, tinha que ter manutenção, hoje as coisas estão apodrecendo". (Egresso, 16 anos).

Percebemos que há um desejo de ter uma escola com infraestrutura, higienizada, de qualidade. Muitos adolescentes apontam em seus discursos a violência no interior e fora das escolas: "É embaçado estudar, cabuloso porque tem treta com a gurizada se for pra escola tem que brigar, aí ou mata ou eles me matam, pra voltar a estudar só se sair do bairro, porque no bairro onde moro tem treta com outros". (Interno, 16 anos).

Por isso que na escola há separação por turmas, justamente para evitar esses aglomerados. Porém, no fenômeno pesquisado, mesmo que haja uma separação por turmas, os bairros se unem e formam seus grupos que extrapolam os muros e as salas de aula das escolas, formando gangues. Segundo Graciani (1997, p. 117):

A intensidade dessas relações (formação de gangs) com o grupo podem explicar-se pela necessidade de proteção ante à violência e agressividade do meio ambiente e também como elemento de defesa. Esses mesmos aspectos permitem compreender a estabilidade de suas relações e dos marcos afetivos. Tanto assim é que a maioria deles se trata como "manos" ou "manas".

\section{Perspectivas de VIDA}

Quando entrevistados sobre qual a perspectiva de vida que eles têm no momento e qual gostariam de ter, a palavra geradora mais narrada pelos egressos e internos aponta muitos sonhos frustrados e também "roubados" pelas questões sociais, familiares, ou até sonhos que são simples, mas parecem distantes. "Gostaria que fosse boa, e pra ser bom teria que ter a família de volta, ter os pais juntos de novo, tem três anos que meus pais se separaram. (Egresso 17 anos); Meu sonho já passou." (Egresso, 15 anos).

Esses depoimentos mostram a limitação das perspectivas de vida em razão das experiências precárias que eles tiveram. Graciani (1997, p. 107) explicita que:

O "desvio social" centra-se no problema de condutas: alcoolismo, drogatização, violência e várias outras formas de inconformidade social, de falta de realismo e compromisso social dos jovens, de sua "condição parasitária", de suas frustrações ante os erros e incapacidades dos maiores, de sua rebeldia ante o mau uso da sua autoridade por parte dos adultos, de suas desesperanças por suas aspirações truncadas, por crises sociais que os 
afetam diretamente produzindo formas de marginalidade de diversos tipos ou a denominada "delinquência juvenil".

Entretanto, diversos adolescentes narraram expectativas contrárias e animadoras.

Quero estudar, ajudar minha mãe, ter uma carreira no Exército. Meu objetivo é seguir em frente e realizar meu sonho. (Egresso, 16 anos).

Construir uma família, ter minha casa, ganhar uns mil e poucos reais para sustentar a família e não fazer nada de errado. (Egresso, 16 anos).

Hoje é ruim - porque não tem como ficar perto da mãe, vó, de ninguém. Cadeia é sinistro, tem que dormir com um olho aberto e o outro fechado, mas vou lutar para ser mestre de obra, fazer altas casas, quero estudar pra ser isso mesmo. (Interno, 17 anos).

Sair daqui, terminar os estudos, enquanto isso fazer cursos, quero fazer auxiliar administrativo, curso de informática, fazer medicina ou odontologia, pra ganhar bem, sei que tenho que estudar pra ganhar bem. (Interno, 14 anos).

Mudar de vida, trabalhar, continuar estudando e não aprontar mais pra não vir pra cá. Cadeia não é lugar de gente não, ficar preso com um monte de homem. (Interno, 15 anos).

Quero ter uma filha, esposa, quero ser fiel pra ela e dar muito amor e carinho. Quero ter uma fazenda com um monte de boi no pasto e quero fazer as coisas certas. Quero fazer parte de uma paróquia, me aproximar mais de Deus. (Interno, 16 anos).

Pelos relatos dos adolescentes compreendemos e interpretamos que eles possuem o desejo de ter direitos realizados, o direito a uma vida digna com amorosidade familiar e social, uma profissão para dar conforto para seus entes queridos e estudar como um caminho para efetivar essas conquistas. Então, refletimos com Graciani (1997, p. 112) que: “A problemática não está no menor que tem que atuar por fora das normas, reside na estrutura social, no ordenamento e na dinâmica da sociedade que o obriga compulsoriamente a esses tipos de conduta ao negar-lhe as possibilidades normais da vida".

Com base nas informações colhidas, interpretamos que a condição de vulnerabilidade dos adolescentes do Centro Socioeducativo começa com a negação do direito a ter suas necessidades sociais básicas atendidas e também com a concepção negativa que eles têm de educação, da escola. Relaciona-se com a educação bancária denunciada por Freire em que resta 
aos alunos decorar temas e circunstâncias insignificantes para o mundo vida. Tais conhecimentos desenvolvidos de forma fragmentária geralmente não se associam com a realidade existencial concreta dos alunos. $O$ hábito da aprendizagem auditiva leva à passividade intelectual e a educação ensinada dessa forma leva à castração, não dá prazer, não estimula a criatividade nem tampouco leva a anseios de liberdade.

\section{CONSIDERAÇÕES FINAIS}

Esta pesquisa considera que há muitas semelhanças nas informações dos adolescentes internos e egressos quando denunciam em suas narrativas a discriminação, a rotulação e a estigmatização social por terem cumprido alguma medida socioeducativa.

Compreendemos e interpretamos que os adolescentes em conflito com a lei são"filhos" de um sistema que os gerou, tirou-lhes direitos e sonhos, quer seja pela negação de condições econômicas e sociais satisfatórias, quer seja porque procura esconder, silenciar e invisibilizar o que ela mesma está produzindo.

O Estatuto da Criança e do Adolescente é considerado um documento modelo de direitos humanos. Ele foi pensado e implementado para garantir, de forma prioritária, os direitos sociais básicos de toda infância e adolescência, visando a defendê-las e protegê-las integralmente da delinquência. No entanto, na prática, o ECA não se efetiva.

A negação dos direitos humanos básicos, tais como alimentação, vestuário, moradia, saneamento básico, saúde e educação, gera profundas desigualdades sociais e, consequentemente, surgem outros problemas, como desajustes familiares, alcoolismo, drogatização, violência física e simbólica que, na realidade, empurram com violência o adolescente a cometer atos infracionais.

Ao cometer atos infracionais, são aprisionados no Centro Socioeducativo que, por mais pretensamente educativo que seja, ao invés de ressocializar, aprofunda o conflito com a lei. Segundo Foucault (1987, p. 160), isso ocorre porque:

O sistema prisional em seu arranjo físico, suas estruturas de disciplina, sua organização hierárquica, sua vigilância constante, as técnicas disciplinares, compreendidas como o controle sobre o espaço e o tempo, além da vigilância e do poder, alia-se a várias formas sutis de aprisionamento dos corpos. 
A questão dos adolescentes em conflito com a lei é um desafio a cada um de nós, aos vários seguimentos sociais e, principalmente ao Estado, que com boa vontade e seriedade poderia promover uma distribuição de renda mais equalizada para não empurrar esses meninos para o fosso da criminalização. Isso significa e exige de cada cidadão, do poder público e da sociedade a colocação de crianças e adolescentes como prioridade de suas preocupações e ações, além de colocá-los a salvo de toda forma de opressão, negligência, discriminação, exploração, violência e crueldade.

Outro desafio é proporcionar uma educação, não baseada na memorização, mas na ação dialógica freireana, que parte das condições existenciais dos alunos mergulhados em suas vivências para desenvolver os conteúdos pedagógicos levando em conta as suas necessidades concretas.

A Educação Integral do Programa Mais Educação acena com essa perspectiva libertadora, pois ao mesmo tempo em que dá condições ao educando de permanecer na instituição escolar durante os dois períodos (matutino e vespertino), propicia formação intelectual (estudo da Linguagem e das Ciências) e considera imprescindível a sensibilização da criança e do adolescente para compreender e vivenciar o meio ambiente com sustentabilidade, as atividades de esporte e lazer, os direitos humanos, as diversas formas de arte (a exemplo do artesanato, dança, música, teatro, cinema, escultura), cultura digital e as relações sociais fundadas em princípios éticos.

Dessa forma, o inédito viável freireano é bem-vindo como luta para superar, gradativamente, os baixíssimos índices de aprendizagem e construir uma realidade social e educacional inclusiva com direito a experienciar o mundo vida com mais dignidade.

\section{YOUTH OFFENDERS' PERCEPTIONS OF THEIR EXPERIENCES IN THE SOCIO- EDUCATIVE CENTER OF CUIABÁ}

ABSTRACT: This article describes, understands, and interprets the youth offenders' perceptions of their experiences in the Socio-Educative Center of Cuiabá. The research is of qualitative, phenomenological, and dialectic nature and is based primarily on the thought of Foucault, Paulo Freire, Graciani, and Volpi. The information gathered through direct observation and interviews show that the organization of this institution promotes violence in its interior and, instead of contributing to the re-socialization 
process it enhances the continuous conflict with the law. The challenge is for the State to carry out social reforms that provide a fair distribution of income and enable the adolescents to overcome their condition of vulnerability and social and educational exclusion.

KEYwords: Perceptions. Youth offenders. Experience. Socio-educative Center.

\section{PERCEPCIONES DE LOS ADOLESCENTES EN CONFLICTO CON LA LEY SOBRE SUS EXPERIENCIAS EN EL CENTRO SOCIOEDUCATIVO DE CUIABÁ}

RESUMEN: En este artículo describe, comprende e interpreta las percepciones de los adolescentes en conflicto con la ley sobre sus experiencias en el Centro Socioeducativo de Cuiabá. La investigación es cualitativa de acuño dialéctica fenomenológica y se basa principalmente en el pensamiento de Foucault, Paulo Freire, Graciani, y Volpi. Las informaciones recopiladas a través de la observación directa y entrevistas muestran que la organización de esta institución promueve la violencia en su interior y en lugar de contribuir para resocializar, potencializar el continuo conflicto con la ley. El desafío pasa por el Estado en el sentido de llevar a cabo reformas sociales que proporciona una justa distribución de renta y, por tanto, permitirá al adolescente a superar la condición de vulnerabilidad, de exclusión social y educativa.

Palabras clave: Percepciones. Adolescentes en conflicto con la ley. Vivencias. Centro Socioeducativo.

\section{REFERÊNCIAS}

BICUDO, M. A. V.; ESPOSITO, V. H. C. (Org.). Pesquisa Qualitativa em educação - um enfoque fenomenológico. 2. ed. Piracicaba: Editora Unimep.1997.

BRASIL. Constituição (1988) Constituição da República Federativa do Brasil. 35. ed. São Paulo: Saraiva, 2005.

. Conselho Nacional dos Direitos da Criança e do Adolescente. Sistema Nacional de Atendimento Socioeducativo - SINASE. Brasília: Conanda, 2006.

. Lei no 8.069, de 13 de julho de 1990. Dispõe sobre o Estatuto da Criança e do Adolescente e dá outras providências. Diário Oficial [da] União, Poder Executivo, Brasília, DF, 16 jul. 1990.

FOUCAULT, M . Microfísica do poder. Rio de Janeiro: Graal, 1995.

. Vigiar e punir: história da violência nas prisões. Petrópolis: Vozes, 1997. 
FREIRE, Paulo. Pedagogia do oprimido. São Paulo: Paz e Terra, 2005. . Pedagogia da Autonomia. São Paulo: Paz e Terra, 1996.

GRACIANI, M. S. S. Pedagogia Social de Rua. São Paulo: Cortez, Instituto Paulo Freire, 1997.

MARTINS, J. Um enfoque fenomenológico do currículo: educação como poésis. São Paulo: Cortez, 1992.

MARTINS, J.; BICUDO, M. A. V. A pesquisa qualitativa em psicologia: fundamentos e recursos básicos. São Paulo: Moraes/Educ., 1989.

REZENDE, A. M. de. Concepção fenomenológica da educação. São Paulo: Cortez, 1990.

VEIGA-NETO, A. Foucault e a Educação. Belo Horizonte: Autêntica, 2003.

VOLPI, M. (Org.). O adolescente e o ato infracional. São Paulo: Cortez, 1997.

Maria da Anunciação PInheiro Barros NetA: Doutora em Educação pela UNICAMP, é professora do Programa de Pós-Graduação em Educação (PPGE) e pesquisadora do Grupo de Pesquisa em Movimentos Sociais e Educação (GPMSE).

E-mail: barrosneta@smail.com

Josiane TOMAZ dA SiLVA: Graduada em Psicologia pela Universidade Federal de Rondônia (UNIR), mestre em Educação pela Universidade Federal de Mato Grosso (UFMT). Atualmente é Psicóloga da Clínica Essência.

E-mail: josianetomaz@smail.com 